\title{
RECONTAR-SE EM CONTOS: \\ SABERES E VIVÊNCIAS EM CONTAÇÕES DE HISTÓRIAS NA EDUCAÇÃO NÃO FORMAL
}

\section{RETELLING IN TALES: KNOWLEDGE AND EXPERIENCES IN THE TELLING OF STORIES IN NON-FORMAL EDUCATION}

\author{
Alice Costa Macedo - UFRB/Brasil \\ Bianca Anjos dos Santos - UFRB/Brasil \\ Kenia Regis Lemos - UFRB/Brasil
}

\begin{abstract}
RESUMO: A educação não formal acontece para além dos muros das escolas: trata-se de um universo que atua, sobretudo, com a liberdade e a formação de cidadãos. Com base neste contexto, o objetivo desta pesquisa foi buscar compreender, em um espaço de educação não formal, de que modo as crianças escutam as histórias, interpretam e constroem estratégias para recontá-las. Foi realizada uma pesquisa qualitativa, do tipo exploratório e corte transversal. Definiu-se uma etapa com bases antropológicas, a partir de um formato etnográfico (observações participantes e registros em diário de campo) e outra mais voltada à proposta de uma pesquisa-ação (atuação do pesquisador como mediador/monitor/educador, na modalidade de contação de histórias). O levantamento de dados ocorreu em um Projeto Social na cidade de Amargosa, Bahia, o Ponto de Leitura, que atende aproximadamente entre 35 e 40 crianças. Foram realizadas 11 oficinas de contação de histórias com a participação de 10 crianças por encontro. Tais vivências permitiram acessar as memórias infantis, os saberes de cada um, assim como suas experiências cotidianas, ao recompor, reconstruir e/ou renegociar concomitantemente a sua autoimagem. Através do universo simbólico apresentado pelas narrativas, as crianças puderam encontrar um meio para recontar seus enredos pessoais. Ali elas edificaram um espaço para catarse, para desabafo, para troca e compartilhamento de angústias, na parceria de um adulto que pôde ser continente a tudo isso, mediando contos, narrativas e sensações, todos permeados pela arte.
\end{abstract}

Palavras-chave: Contação de histórias. Educação não formal. Psicologia da Educação.

ABSTRACT: Non-formal education happens beyond the walls of schools: and is about a universe that acts, mainly, with the freedom and formation of citizens. Based on this context, the objective of this research was to comprehend, through a space of non-formal education, how children listen to stories and interpret and construe strategies to retell them. A qualitative research of exploratory and cross-sectional character was performed. Then was defined a stage with anthropological bases, starting from an ethnographic format (participating observations and records in a field journal) and another more aimed at a proposal for an action-research (performance of the researcher as mediator/monitor/educator, in the modality of telling stories). A survey was made at a Social Project in the city of Amargosa, State of Bahia - Brazil, named "Ponto de Leitura" that tends to approximately 35 to 40 children. Eleven storytelling workshops were performed with the participation of 10 children per visit. These experiences permitted access to the memories of the children, the knowledge of each one, as well as their 
everyday experiences, while recomposing, rebuilding and/or renegotiating concomitantly, their self-image. Through the symbolic universe presented by the narratives, the children were able to find a way of retelling their personal tales. There they found a space for catharsis, unburdening, for sharing and exchanging their torments, alongside an adult that was able to be continent to all of it, mediating tales, narratives, emotions, all permeated by art.

Keywords: Storytelling. Non-formal Education. Psychology of Education.

\section{INTRODUÇÃO}

A educação não formal acontece para além dos muros das escolas: trata-se de um universo que atua, sobretudo, com a liberdade e com a formação de cidadãos. No contexto não formal, deve-se destacar que há, sim, rigor metodológico, intencionalidade e objetivos claros e consistentes. Por outro lado, desenham-se inúmeras estratégias que podem deslizar livremente por meio da arte, da cultura, dos saberes populares, das memórias e histórias de diferentes modalidades.

Conforme Freitas (2007), existe diferença entre as formas de ensino: a educação formal está associada às intuições convencionais (escolas, universidades, escolas técnicas etc.); a educação informal é aquela relacionada às modalidades educacionais que o sujeito encontra ao longo de sua vida (na rua, na igreja, nos vizinhos, nos parques, praças etc); e a não-formal, apesar de ter uma organização e às vezes certificação, diferencia-se em relação à carga horária, ao espaço físico, e com adaptações metodológicas dos conteúdos. Portanto, estudos como este permitem esclarecer os diferentes tipos de ambientes educacionais e refletir sobre suas estratégias metodológicas o os tipos de impactos que causam na sociedade.

De acordo com Gohn (2006), a educação não-formal desenvolve um processo de aprendizagem diferenciado que prepara esse sujeito como cidadão, tornando-o um indivíduo político, senhor dos seus direitos e potencializando suas habilidades de maneira coletiva em suas comunidades. Esta modalidade proporciona também "a aprendizagem de conteúdos que possibilitem aos indivíduos fazerem uma leitura do mundo do ponto de vista de compreensão do que se passa ao seu redor" (GOHN, 2006, p. 28), viabilizando uma interpretação crítica da realidade social que o cerca.

Outro aspecto a ser salientado nesse trabalho é a importância do educador: sabese que na educação formal o professor é o educador; mas, na educação não-formal,

Educação, Psicologia e Interfaces, Volume 4, Número 1, p. 92-105, Janeiro/Março, 2020.

ISSN: 2594-5343. DOI: https://doi.org/10.37444/issn-2594-5343.v4i1.182 
segundo Gohn (2006), a imagem de educador não se atribui a uma única pessoa e sim ao “outro" com o qual o indivíduo vem a se relacionar nesse espaço. Já na educação informal esse papel cabe aos familiares, amigos, pares ou mesmo vizinhos.

Com relação ao espaço físico em que ocorrem essas formas de aprendizagens, ressalta-se que os espaços de educação formal são "instituições regulamentadas por leis, organizadas segundo diretrizes nacionais", ocorrem dentro dos muros dos espaços institucionalizados onde se obtém um título formal. Sobre os espaços físicos das outras duas modalidades: os territórios da educação não-formal dizem respeito à história de vida de seus protagonistas, sempre extramuros da escola; enquanto, no caso da educação informal, os espaços educativos são delineados pelas marcas identitárias de seus atores nacionalidade, sexo, religião, etnia, entre outros (GOHN, 2014).

Ainda de acordo com Gohn (2006), a organização dos conteúdos de ensino e metodologias utilizadas nessas modalidades também são distintos: os conteúdos da educação formal estão organizados sistematicamente, têm um conjunto de regras e são separados por áreas de conhecimentos que seguem um parâmetro comum nacional. $\mathrm{Na}$ modalidade educacional não-formal não existe essa divisão das áreas do conhecimento, todos os conteúdos e as metodologias estão interligados em cada atividade proposta e têm o objetivo principal relacionado ao aprendizado social, coletivo e interativo (GOHN, 2006). Na educação informal o conhecimento desenvolve-se a partir do contato com o meio em que o sujeito está inserido, em que desenvolve sua linguagem e comportamentos de acordo com sua crença e cultura.

Para Fávero (2007), ao se pensar a educação não-formal, sugere-se uma atuação extraescolar, como um complemento da escola, mas sabemos que, na verdade, sua proposta suplanta esta perspectiva, pois delimita espaços de definição de identidades, resgate de memórias e saberes, além de possibilitar circunstâncias propícias para a militância e o empoderamento popular. Fávero (2007) também relata sobre um contexto histórico mundial que ajuda a entender essas modalidades de ensino. A educação não formal teve início em 1960, segundo Marques e Freitas (2017), “numa época de conjeturas políticas e sociais propícias à criação de novos espaços educativos” (p. 1089).

No contexto do regime militar, na década de 1960, por exemplo, o Brasil enfrentou uma forte crise no setor escolar, a democracia encontrava-se ameaçada em seus pilares mais valiosos e, assim, multiplicaram-se os espaços educacionais diferenciados das 
escolas formais, mas que trouxessem possibilidades de resistência, reflexão crítica e debates. A partir deste período, foi se reconstituindo uma nova visão da educação que se dividia, segundo a UNESCO (Organização das Nãções Unidas para a Educação, a Ciência e a Cultura), em três categorias: educação formal, informal e não-formal.

Com base neste contexto, o objetivo desta pesquisa foi buscar compreender, em um espaço de educação não formal, de que modo as crianças escutam as histórias, interpretam e constroem estratégias para recontá-las. Para tanto, contou-se com a atuação de um dos pesquisadores na posição de mediador/monitor/educador, na modalidade de contação de histórias, em um projeto social (Ponto de Leitura), na cidade de Amargosa, Recôncavo da Bahia.

\section{MATERIAL E MÉTODO}

\section{Tipo de Estudo}

Trata-se de uma pesquisa qualitativa, do tipo exploratório e corte transversal. Buscou-se, em uma primeira etapa, uma revisão da literatura acerca da Educação Não Formal nesses espaços de militância, associações ou organizações da sociedade civil. Posteriormente, definiu-se uma pesquisa de campo, com bases antropológicas, a partir de um formato etnográfico e outro voltado à pesquisa-ação.

\section{Participantes}

O levantamento de dados ocorreu em um Projeto Social em uma cidade de pequeno porte no Recôncavo da Bahia, Amargosa, que abriga uma população estimada menor do que 40.000 habitantes. O Projeto nomeado como Ponto de Leitura localiza-se no bairro da URBIS II, situado em uma região periférica relativamente ao centro da cidade, e tem como representante legal Adelia Maia Sampaio, pedagoga, coordenadora geral das ações pedagógicas e administrativas. Essa instituição atende aproximadamente entre 35 e 40 crianças moradoras da mesma comunidade onde atua o projeto e três adolescentes de faixa etária entre 13 a 15 anos que são monitores da instituição. Existe um cronograma mensal de voluntários: esses atuam de forma itinerante, podem propor uma oficina pontual com início, meio e fim no mesmo dia, ou um projeto longitudinal, 
atuando em um maior intervalo de tempo, como um mês ou um ano. O Ponto de Leitura funciona 4 vezes na semana mediante doações e pessoas voluntárias.

\section{Procedimentos}

$\mathrm{Na}$ primeira etapa da pesquisa de campo, utilizou-se o modelo etnográfico (LAPLANTINE, 2004), herança da Antropologia: foram realizadas observações participantes e registros em diário de campo. As visitas ao Ponto de Leitura iniciaram-se em setembro de 2018, tendo se estendido até julho de 2019. O projeto era previamente conhecido pelas pesquisadoras, de modo que uma delas é residente da cidade de Amargosa e foi moradora do bairro URBIS II, local de atuação do Projeto Social em questão. Esse contato prévio facilitou o vínculo entre pesquisadoras e campo e permitiu que o estudo ocorresse de forma fluida sem quaisquer intercorrências no que tange à relação com seus interlocutores.

$\mathrm{Na}$ segunda etapa, foram realizadas 11 oficinas de contação de história com as crianças participantes do Ponto de Leitura. As oficinas contavam com a participação de uma média de 10 crianças que, ao se sentarem em círculo, escutavam atenciosamente a contação de histórias e posteriormente esboçavam, elas mesmas, todo o enredo mágico do conto. Por fim, a oficina se encerrava com propostas artísticas e/ou jogos que envolviam a interpretação sobre a narrativa, habilidades linguísticas, ou ainda atividades relacionadas à capacidade de abstração. Nesta fase, realizou-se, portanto, uma pesquisaação (GONÇALVES, 2005) cujos acontecimentos foram registrados também em diários de campo.

\section{Modelo de Análise dos Dados}

Para análise dos dados, foi utilizado o olhar etnográfico, herança da Antropologia, na confecção do texto etnográfico final. Além disso, relativamente à etapa da pesquisaação, com base nos registros em diário de campo a respeito do que ocorreu nos encontros com as crianças, foi possível tecer um corpus de análise, sobre o qual debruçamo-nos a partir de uma escuta psicanalítica. A contação de histórias, nesta presente pesquisa, receberá um olhar baseado na perspectiva psicanalítica de Pokorski e Pokorski (2013) e Peres, Naves e Borges (2018).

Educação, Psicologia e Interfaces, Volume 4, Número 1, p. 92-105, Janeiro/Março, 2020.

ISSN: 2594-5343. DOI: https://doi.org/10.37444/issn-2594-5343.v4i1.182 


\section{RESULTADOS E DISCUSSÃO}

O Ponto de Leitura revela-se atualmente como um Projeto Social organizado, pensado minuciosamente em seus mínimos detalhes pela educadora e fundadora Adélia Maia. Hoje funciona em uma casa alugada em um bairro periférico da cidade, a URBIS II, com estradas de barro e pouco acesso a serviços básicos de saneamento. Há ainda, em torno desta comunidade, uma série de representações sociais que circulam na cidade de Amargosa - BA e são associadas à violência, o que prejudica não só a imagem que a sociedade constrói dos moradores desta localidade, mas também impacta negativamente sua própria identidade.

A casa onde funciona esta iniciativa possui um jardim na entrada, construído pelos próprios membros do projeto e decorado com pedaços de pneus pintados de cores diversas. Em seu interior, encontramos um salão principal, onde ocorrem as oficinas e atividades maiores; à esquerda um quarto que contém a pequena biblioteca do Ponto de Leitura com uma estante repleta de livros aos quais as crianças têm livre acesso; a seguir, mais um quarto destinado a outras oficinas e onde estão materiais escolares e sucatas que podem ser utilizados pelas crianças e monitores; por fim, uma cozinha e um banheiro para o uso coletivo.

Em sequência, as oficinas dedicadas à contação de histórias serão descritas e acompanhadas por sua respectiva discussão com base no referencial teórico supracitado. Deve-se salientar que todas as oficinas eram iniciadas com uma música de boas vindas entoada pelas crianças e, em seguida, em uma roda, sentadas no chão, elas se apresentavam, dizendo nome, idade e o sonho de suas vidas (normalmente a profissão que gostariam de assumir quando adultas).

Quase todos os encontros eram iniciados com a leitura de um livro: as crianças recontavam as histórias, compartilhando a releitua. Em círculo elas se sentavam e cada uma relia uma página; as releituras eram acompanhadas por performances, por representações através dos corpos ou mudanças na voz. O momento em que elas recontavam as narrativas trouxe dados cruciais para este presente estudo, pois revelou análises preciosas sobre a capacidade de recriarem, interpretarem e reinterpretarem as histórias. No fim de todas as oficinas eram realizadas atividades lúdicas a fim de

Educação, Psicologia e Interfaces, Volume 4, Número 1, p. 92-105, Janeiro/Março, 2020.

ISSN: 2594-5343. DOI: https://doi.org/10.37444/issn-2594-5343.v4i1.182 
proporcionar um ambiente mais acolhedor, visto que a contação de histórias trazia à tona muitos conteúdos fortes e marcantes para as crianças. O dia era finalizado com um lanche.

\subsection{Entre diários e oficinas: recontando narrativas e sentidos}

Na primeira oficina, o livro apresentado trabalhou com o tema: "Tomar banho é uma encrenca”, a leitura foi compartilhada. Em seguida, um vídeo contextualizou a leitura: "por que tomar banho todos os dias?" Depois foi solicitado que eles relatassem o que entenderam.

Houve provocações e problematizações sobre a narrativa com o objetivo de desafiar os participantes a exporem ideias e opiniões, eles interagem e participam, manteve-se o bate-papo. Dentre as inúmeras orientações, os participantes puderam vivenciar, numa linguagem simples, de que maneira podemos manter a saúde e a higiene pessoal.

A oficina fomentou reflexões entre as crianças, a saber o olhar sobre o próprio corpo e o que ele exala: fluidos, odores, aromas, secreções. Foi possível trabalhar com emoções significativas na infância: asco, vergonha, tristeza, medo, raiva. A intervenção trouxe ainda um aspecto importante: o olhar sobre si mesma e sobre o outro, baseado na aceitação do que é natural em nossa própria anatomia humana, por mais que a sociedade tenha "demonizado" esta natureza. Desse modo, surgiram desconstruções de preconceitos, verdades inconfessáveis e, sobretudo, exposição do que há de mais sombrio e, ao mesmo tempo, puro em cada sujeito. Exposição e acolhimento do risível e repulsivo em si e no outro, ao buscar o máximo de isenção de preconceitos.

O encontro seguinte abordou hábitos saudáveis, focando mais na higiene das mãos. Logo após, iniciou-se uma dinâmica: as crianças foram divididas em duplas. Um ficava de olhos fechados (com uma venda nos olhos) e o outro com a tinta guache, com objetivo de sujar a mão do colega e ensinar o colega a lavar as mãos adequadamente.

Qual foi o propósito da brincadeira? Era colocar a tinta guache nas mãos do colega que estava com a venda e ensinar como lavar as mãos. Aquele colega que, no final, estivesse com a mão toda suja de tinta não tinha aprendido a lavar a mão direito. Eles se divertiam demais quando tiravam a venda dos olhos. Depois, foram todos para o quintal para a criançada lavar as mãos. 
Recontar-se em Contos: saberes e vivências em contações de histórias na Educação Não Formal

Foi um momento importante no qual os participantes compreenderam os benefícios para a saúde de manter hábitos saudáveis. Além disso, trata-se de uma atividade sensorial, que é intensificada pela exclusão dos sentidos visuais. A criança venda os olhos, para sentir o tato, a mão, a pele, o toque, dando ênfase a outras vivências sinestésicas. Vendar os olhos e confiar no colega que ensina e guia também traz uma experiência significativa para a criança, porque intensifica os laços de confiança com o outro e investe na conexão entre os corpos atuantes na dinâmica.

Em outro dia, trabalhou-se com o livro da coleção "Bia" com o tema "Ganhar e Perder". A ideia desse tema surgiu em uma oficina anterior, a partir de uma dinâmica realizada, pois algumas crianças ficaram tristes quando perderam o jogo. Como de costume, as crianças recontaram a pequena história de Bia, cada leitor mirim leu uma folha. A cada página uma performance diferente, uma dramatização característica de cada um, uma releitura, uma reinterpretação.

Depois de lerem a história, iniciaram-se as perguntas, acompanhadas da ideia de que nem sempre perder é ruim. Então eles começaram a se ver na história e relembrar suas próprias marcas e vivências cotidianas: "Bia perdeu o gol e ficou triste"; "Oh, pró1, eu quando perco um gol eu também fico triste"; "Ela foi treinar mais"; "Eu aprendi, pró, que mesmo sem a gente ganhar, os outros ficam tristes, mas batem palmas para gente"; "Eu também fico triste quando não passo na prova"; "Bia perdeu o gol para ela ver que nem sempre a gente ganha"; "A gente nunca pode desistir"; "Na escola pró tem um colega que ela só quer ganhar, aí um dia o time dela perdeu e ela não queria sair da quadra, e teve briga. Porque ela não aceitava perder"; "Aqui no bairro tem um desfile de modelo, mas só ganham três e as outras que não ganharam ficaram chorando"; "Tem um menino no Ponto de Leitura, o grupo 'homens de ação' que reforma casas e reformou a casa dele, aí ele falou: Eu nunca ganho na escola, mas eu ganhei uma casa”; "Oh pró, eu assisti na televisão um menino do meu tamanho que entrou na faculdade"; "Eu nunca tinha recebido uma nota vermelha, mas quando cheguei no $7^{\circ}$ ano recebi duas, eu fiquei arrasada, aí estudei para recuperar e não recebi mais, porque sei que não posso perder”.

\footnotetext{
${ }^{1}$ Pró: diminutivo ou alcunha; nome carinhoso que as crianças, no estado da Bahia, costumam usar para chamar suas professoras.
} 
Sugere-se que o tema foi muito mobilizador, por isso as crianças pareciam tão agitadas com a conversa pós-leitura e sentiam a necessidade de descarregar a ansiedade através da ludicidade. Por isso foram brincar no final do dia, antes mesmo de concluir a oficina.

Identificou-se, a partir das duas oficinas anteriores, que havia uma questão emergente entre as crianças: a tristeza diante do fracasso. Quando este tema veio à tona, as crianças pareciam inquietar-se, como em uma catarse: vomitavam todos os tipos de desabafos e experiências frustrantes, dentre as quais destacaram-se algumas que foram transcritas anteriormente. Elas precisavam simplesmente falar e, diante das inquietações, construir lado a lado esse espaço psíquico para a elaboração de suas próprias narrativas que dialogavam com a história da personagem principal do conto ("Bia”).

A proposta da oficina subsequente foi trabalhar com as emoções: alegria, tristeza, raiva, medo e nojo, assim mostrando que todas as emoções têm sua importância. Não existe sentimento melhor ou pior.

Depois de assistir o trailer do filme "Divertidamente", as crianças entenderam qual seria a proposta da oficina. Elas deveriam desenhar ou escrever uma das emoções que mais chamasse a atenção e explicariam o porquê. Algumas justificativas marcaram os monitores: "eu fico alegre quando eu venho para o ponto de leitura e fico triste quando a pró Adely fica doente"; "Eu fico alegre quando minha mãe me deixa brincar na rua e fico com medo quando fico em casa sozinho e quando fico em casa sozinho eu vou para rua porque fico com medo de ficar em casa e na rua não tenho medo"; "Eu fico triste quando fazem bullying comigo, tenho nojo de pessoas sem caráter e fico com raiva quando me acusam de algo que não fiz"; "Tenho nojo de gente que pega o bago de jaca mole chupa e cospe, morro de nojo disso"; “Tenho raiva de pessoas que me chamam de 'Lezado' e 'Ladeira' e fico triste também"; "Tenho raiva de gente falso"; "Tenho nojo de barata"; "Fico feliz quando estou no ponto de leitura".

Este encontro pareceu dar continuidade à proposta da oficina anterior de trabalhar os conteúdos psíquicos e construir coletivamente um espaço afetivamente seguro para que eles possam vir à tona. As crianças necessitam de um momento em que possam falar sobre isso, expressar, pôr para fora. Muitas vezes, o monitor precisa apenas estar presente, ser continente a esta sensação, sentar-se como espectador para abraçar cada experiência e respeitar as emoções que se associam a ela. O adulto presente não constrange, não 
Recontar-se em Contos: saberes e vivências em contações de histórias na Educação Não Formal

censura o que é dito, muito menos responde com "selvagerias analíticas" ou "interpretoses irresponsáveis". Ou seja, o mediador da atividade não precisa ser analista, psicólogo, mas precisa oferecer sua escuta e seu acolhimento, revelando também o que sente, em uma relação horizontal, de igualdade perante a criança. Isso não significa que esse medidador não precise ter uma formação ou uma experiência específica, ou ainda, que, sendo ele um estudante em formação, não precise de um supervisor. Pelo contrário, a educação não formal exige esse rigor metodológico.

Em outra tarde, uma oficina foi ministrada por outra voluntária, que não era membro deste presente projeto. A atividade envolvia a contação da história "Maraí a Vitória Régia". Perguntas foram lançadas: quais super-heróis vocês queriam ser? Depois usaram a imaginação para escolher um nome de super-herói que ainda não existe. Apareceram alguns, como mulher-raio, mulher-sol etc. Depois vieram mais instigações: se vocês pudessem salvar uma pessoa, como salvariam?

Para finalizar, foi pedido que eles desenhassem um super-herói que gostariam de ser. Os leitores foram desafiados a se identificarem com um herói, um personagem criativo e inovador, criar seu grito de guerra e justificar por que eles escolheram esse super-herói. Para encerrar, as produções foram apresentadas e os participantes socializaram suas criações. Dentre vários desenhos, serão descritos alguns: mulher elétrica ou mulher maravilha, porque salvaria as pessoas; o menino mais forte do mundo, porque ajudaria os cadeirantes a subir escadas; "leide bong", heroína que ajudaria as pessoas e as crianças; super-nuvem, porque ajuda as pessoas que não têm água (neste caso, uma questão muito voltada à realidade de uma criança que vive no Sertão, no contexto rural).

Em sequência às oficinas que iluminam conteúdos psicológicos, após o trabalho com a questão do "ganhar e perder" associada à frustração e à tristeza; e também em sequência à provocação sobre as cinco emoções básicas; esta dinâmica sobre super-heróis parece propor saídas para situações de medo, frustração, raiva e tristeza: a busca pela potência, que se identifica com os personagens associados à força, beleza, bondade, alegrias. No fim, a monitora propõe que esta potência esteja também direcionada ao mundo externo, ou seja, à busca em se relacionar positivamente com o outro, em ações de solidariedade.

Educação, Psicologia e Interfaces, Volume 4, Número 1, p. 92-105, Janeiro/Março, 2020.

ISSN: 2594-5343. DOI: https://doi.org/10.37444/issn-2594-5343.v4i1.182 
$\mathrm{Na}$ oficina seguinte, o tema foi Pinóquio, personagem assíduo e querido por eles. Todos leram e trouxeram suas reinterpretações teatralizadas da história do pequeno boneco-menino. No término do conto, perguntas sobre a leitura: Qual a ideia principal do conto? O que ocorre quando Pinóquio falta com a verdade? Vocês costumam mentir? Qual a moral da história? Então, eles começaram a contar as próprias vivências: "Pró, um dia eu não queria ir para escola e falei a minha mãe que estava com dor de barriga". "Uma vez eu comi o leite em pó escondido e quando minha mãe chegou eu disse que foi meu irmão". "Outro dia na escola, eu pedi a professora para sair cedo porque eu estava com dor de cabeça, mas era mentira, eu queria ir jogar bola e ela deixou. Porém, nesse dia, minha mãe foi na escola e não me encontrou. Aí, minha mãe quando chegou em casa me deu uma surra de cipó e me colocou de castigo". "Oh pró, mentir não é coisa boa não".

Neste encontro, foram trabalhadas a mentira e suas consequências: Pinóquio é um personagem interessante, porque traz contrapontos associados a valores compartilhados socialmente. À medida que o personagem atua se distanciando dessa "moral", ele vai se "desumanizando", ou seja, ele perde a possibilidade de assumir uma condição verdadeiramente humana e se torna novamente boneco, inanimado, passivo, fantoche, de madeira e não de carne, osso e pele. Diante desse cenário, as crianças mais uma vez desabafam, manifestam o que realmente sentem e pensam, e se expõem tão verdadeiramente que revelam sua relação de confiança com a pesquisadora (principalmente, a que ministrava a contação das histórias), com quem podem ser elas mesmas sem medo de juízos e censuras.

A leitura compartilhada da próxima oficina foi da "Galinha Gabriela". Esse conto relata a história de uma galinha que gosta de trabalhar e seus amigos não a ajudam. Mas, quando ela faz um bolo, todos querem comer, no entanto ela nega porque quando ela estava trabalhando ninguém podia ajudá-la. No término da história, pediu-se que eles contassem o que entenderam da história. Eles contaram que tinham amizades iguais aos amigos da galinha.

Mais uma vez, restituem-se as vozes à infância, e permite-se que elas próprias assumam a autoria de suas histórias: “Oh pró, ontem um amigo na escola que não me ajuda quando preciso na minha tarefa, mas quando eu estou com um lanche ele vem me pedir um pedaço e eu também não dou. Eu sou ruim também”. “Oh pró, aqui mesmo no ponto de leitura tem gente assim, só se aproxima na hora do interesse. Eu odeio gente

Educação, Psicologia e Interfaces, Volume 4, Número 1, p. 92-105, Janeiro/Março, 2020.

ISSN: 2594-5343. DOI: https://doi.org/10.37444/issn-2594-5343.v4i1.182 
Recontar-se em Contos: saberes e vivências em contações de histórias na Educação Não Formal

desse tipo". "A galinha fez certo de comer o bolo sozinha, eu faria o mesmo. O mundo hoje é de interesse. Tô fora!" Foram vários relatos. Logo após, foi sugerido que representassem através de desenho o animal com que mais se identificaram na história. Eles desenharam e cada um apresentou o seu para os colegas.

Quando uma narrativa é lançada, é apresentada a eles uma possibilidade de recontá-la a partir de experiências próprias. Nesse sentido, mais uma vez, a oficina dá lugar a esta oportunidade de elaborar vivências significativas que deixam marcas na infância e que também dizem respeito às relações humanas e ao modo como elas se estabelecem e se consolidam. Na verdade, ali eles encontram um espaço para catarse, para desabafo, para troca e compartilhamento de angústias, na parceria de um adulto que pode ser continente a tudo isso, mediando contos, narrativas, sensações e uma pitada de arte.

Pouco a pouco, nossas oficinas foram se adequando à realidade vivenciada. Em cada oficina, nós percebia-se que algo podia estar "errado", mudava-se a programação. Sendo assim, em uma dessas oficinas percebeu-se que eles gostam de fazer críticas aos colegas por não falarem a norma culta. Desse modo, vimos a necessidade de levar o texto "Nóis Mudemo", que retrata uma história de um aluno oriundo da zona rural: ao chegar na escola atrasado, a professora pergunta o motivo do atraso e ele responde "é porque nóis mudemo onte fêssora". Imediatamente, ela reprime e oprime a resposta na frente de todos os alunos e fala: “Nóis Mudemo, não. Nós mudamos!” A partir daí, todos na sala colocaram o nome dele "nóis mudemo". Resumindo, ele ficou triste e evadiu da escola.

A leitura foi compartilhada. Quando terminou, perguntou-se o que eles acharam e imediatamente eles responderam: "a professora não deveria fazer isso na frente dos outros alunos, eu fiquei com pena dele. Isso é feio!". "Ele fica triste! Mas a gente é criança professora, criança pode! Quem não poderia falar é a professora porque é adulta". "Oh, pró, eu não vou fazer isso mais não, porque eu não gosto que façam isso comigo! A partir de hoje vou parar com isso. Deus não gosta disso, pró!”

A história foi um disparador para abordar questões que envolviam diversos conteúdos importantes para as crianças e que permearam todas as oficinas deste presente projeto do começo ao fim: preconceitos, bullying, identidade, autoimagem, alteridade, emoções, medos. Finalizou-se com mais uma vez um momento de catarse seguido de acolhimento. 


\section{CONSIDERAÇÕES FINAIS}

As narrativas infantis remetem a um mundo fictício, de modo que as crianças podem sentir medo, nojo, ódio, tristeza, vergonha, alegria. Acredita-se que isso acontece devido à possibilidade dos leitores mirins se reencontrarem nas histórias, é uma junção do real com o imaginário. É notório, nas oficinas, observar as emoções e os sentimentos dos leitores mirins de forma significativa. Foram suscitadas a criatividade e a imaginação de modo profundo através da contação de histórias.

Desse modo, eles conseguiram reinterpretar sua própria história e se conhecer nela. É nessa interação com os livros e com os colegas em grupo que eles compartilham suas vivências, conseguem renegociar significados em suas vidas de modo peculiar, assim construindo outras formas de ressignificação. É uma possiblidade de compreender, de ter novas visões de mundo e de si mesmo.

Através do universo simbólico apresentado pelas narrativas, as crianças puderam encontrar uma possibilidade para recontar suas próprias narrativas pessoais. Além disso, a partir do compartilhamento desses enredos míticos entre crianças e adolescentes de 4 a 14 anos, foi possível acessar as memórias infantis, os saberes de cada um, assim como suas vivências cotidianas, ao recompor, reconstruir e/ou renegociar concomitantemente a sua autoimagem.

\section{REFERÊNCIAS BIBLIOGRÁFICAS}

ALEXANDRE, Vanessa. Maraí: a Vitória Régia. Bolsa Nacional do Livro, 2012.

FÁVERO, Osmar. Educação não-formal: contextos, percursos e sujeitos. Educação e Sociedade, Campinas, v. 28, n. 99, p. 614-617, 2007. Diponível em:

<http://www.scielo.br/pdf/es/v28n99/a17v2899.pdf>. Acesso em: 25 out. 2019.

FREITAS, Isaurora Cláudia Martins de. Escola e Organização Não

Governamental: educação formal e não-formal de jovens da periferia de

Fortaleza. Caderno CRH, v. 20, n. 49, p. 77-94, 2007. Disponível em:

<http://dx.doi.org/10.1590/S0103-49792007000100007>. Acesso em: 03 out. 2019.

GOHN, Maria da Glória. Educação Nao Formal, aprendizagens e saberes em processos participativos. Investigar em Educação, v. 1, p. 35-50, 2014. Disponível em:

<http://pages.ie.uminho.pt/inved/index.php/ie/article/view/4>. Acesso em: 29 out. 2019.

GOHN, Maria da Glória. Educação não-formal, participação da sociedade civil e estruturas colegiadas nas escolas. Ensaio: avalíação políticas públicas e Educação, Rio de Janeiro,

Educação, Psicologia e Interfaces, Volume 4, Número 1, p. 92-105, Janeiro/Março, 2020.

ISSN: 2594-5343. DOI: https://doi.org/10.37444/issn-2594-5343.v4i1.182 
Recontar-se em Contos: saberes e vivências em contações de histórias na Educação Não Formal

v. 14 , n. 50, p. 27-38, 2006. Disponível em:

<http://www.scielo.br/pdf/ensaio/v14n50/30405/>. Acesso em: 28 out. 2019.

GONÇALVES, Hortência de Abreu. Manual de metodologia da pesquisa científica. São Paulo: Avercamp, 2005.

LAPLANTINE, François. A Descrição Etnográfica. São Paulo: Terceira Margem, 2004.

MARQUES, Joana Brás Varanda Marques; FREITAS, Denise de. Fatores de caracterização da educação não formal: uma revisão da literatura. Educação e Pesquisa, v. 43, n.

4, out./dez. 2017. Disponível em: <http://dx.doi.org/10.1590/s1517-9702201701151678>.

Acesso em: 02 out. 2019.

MONARI, Manuela. Tomar banho é uma encrenca! São Paulo: Caramelo, 2012.

NICK, Bullard. A Galinha Gabriela. São Paulo: FDT, 2016.

PERES, Silvana Goulart; NAVES, Renata Magalhães; BORGES, Fabrícia Teixeira. Recursos simbólicos e imaginação no contexto da contação de histórias. Psicologia Escolar e Educacional, v. 22, n. 1, p. 151-161, 2018.

POKORSKI, Maria Melania Wagner Franckowiak; POKORSKI, Luís Antônio Franckowiak. O contador de histórias: vínculos e identificações. Estudos de Psicanálise, Belo Horizonte, n. 40, p. 91-100, 2013.

\section{Credenciais da/o/os autora/es}

MACEDO, Alice Costa. Professora Adjunta da Universidade Federal do Recôncavo da Bahia. Graduação, mestrado e doutorado em Psicologia (Universidade de São Paulo). E-mail: alicemacedo@ufrb.edu.br

SANTOS, Bianca Anjos dos. Graduanda em Licenciatura em Letras na Universidade Federal do Recôncavo da Bahia. Pesquisadora Bolsista PIBIC/CNPq entre 2018 e 2019. E-mail: byankaanjinho22@hotmail.com

LEMOS, Kenia Regis. Graduanda em Licenciatura em Letras na Universidade Federal do Recôncavo da Bahia. Pesquisadora Bolsista PIBIC/CNPq 2019-2020. E-mail: kenia_lemos@hotmail.com

Endereço para correspondência: Alice Costa Macedo. Avenida Nestor de Melo Pita, 535 Centro, Amargosa - BA, 45300-000. E-mail: alicemacedo@ufrb.edu.br

Como citar este artigo (Formato ABNT): MACEDO, Alice Costa; SANTOS, Bianca Anjos dos; LEMOS, Kenia Regis. Recontar-se em Contos: saberes e vivências em contações de histórias na Educação Não Formal. Educação, Psicologia e Interfaces, v. 4, n. 1, p. 92-105, 2020. DOI: https://doi.org/10.37444/issn-2594-5343.v4i1.182

Recebido: $11 / 10 / 2019$

Aceito: 20/12/2019.

Educação, Psicologia e Interfaces, Volume 4, Número 1, p. 92-105, Janeiro/Março, 2020.

ISSN: 2594-5343. DOI: https://doi.org/10.37444/issn-2594-5343.v4i1.182 